\title{
SYMPOSIUM
}

\section{Environmental Adaptation, Phenotypic Plasticity, and Associative Learning in Insects: The Desert Locust as a Case Study}

\author{
Patrício M. V. Simões, ${ }^{*}$ Swidbert R. Ott ${ }^{\dagger}$ and Jeremy E. Niven ${ }^{1, \neq}$ \\ *Sensory Neuroscience Research Group, School of Pharmacy and Biomolecular Sciences, University of Brighton, \\ Brighton, BN2 4GJ, UK; †Department of Neuroscience, Psychology and Behaviour, University of Leicester, Leicester, LE1 \\ 7RH, UK; ¥School of Life Sciences, University of Sussex, Falmer, Brighton, BN1 9QG, UK
}

From the symposium "Neuroecology: Neural Mechanisms of Sensory and Motor Processes that Mediate Ecologically Relevant Behaviors" presented at the annual meeting of the Society for Integrative and Comparative Biology, January 3-7, 2016 at Portland, Oregon.

${ }^{1}$ E-mail: J.E.Niven@sussex.ac.uk

Synopsis The ability to learn and store information should be adapted to the environment in which animals operate to confer a selective advantage. Yet the relationship between learning, memory, and the environment is poorly understood, and further complicated by phenotypic plasticity caused by the very environment in which learning and memory need to operate. Many insect species show polyphenism, an extreme form of phenotypic plasticity, allowing them to occupy distinct environments by producing two or more alternative phenotypes. Yet how the learning and memories capabilities of these alternative phenotypes are adapted to their specific environments remains unknown for most polyphenic insect species. The desert locust can exist as one of two extreme phenotypes or phases, solitarious and gregarious. Recent studies of associative food-odor learning in this locust have shown that aversive but not appetitive learning differs between phases. Furthermore, switching from the solitarious to the gregarious phase (gregarization) prevents locusts acquiring new learned aversions, enabling them to convert an aversive memory formed in the solitarious phase to an appetitive one in the gregarious phase. This conversion provides a neuroecological mechanism that matches key changes in the behavioral environments of the two phases. These findings emphasize the importance of understanding the neural mechanisms that generate ecologically relevant behaviors and the interactions between different forms of behavioral plasticity.

\section{Introduction}

Insects, like all animals, learn and store new information about their environment, and use it to modify various behaviors including feeding, predator avoidance, social interaction, and sexual behavior (Papaj and Prokopy 1989; Dukas 2008a; Chittka and Niven 2009). Improved learning and memory capacities are correlated with increased fitness (Dukas and Bernays 2000; Dukas and Duan 2000; Dukas 2008b; Raine and Chittka 2008) but also increased costs (Johnston 1982; Dukas 1999; Mery and Kawecki 2003, 2004, 2005; Burns et al. 2011). Consequently, the learning and memory capacities of a particular species are expected to exhibit natural genetic variation and to be adapted to their ecology and life history. Indeed, insect learning capacities vary widely at the level of individuals, populations and species, and these differences likely reflect adaptations to their environment (Brandes 1991; Lofdahl et al. 1992; Shettleworth 1993; Dukas 1999, 2008a; Ferguson et al. 2001; Raine et al. 2006; Raine and Chittka 2008; Burns et al. 2011; Hoedjes et al. 2011; Ngumbi et al. 2012).

However, learning is not the only way in which insects are shaped by their environments. Many insect species display polyphenism, manifesting two or more distinct alternative phenotypes in response to environmental cues (Nijhout 2003; West-Eberhard 2003; Fusco and Minelli 2010; Moczek 2010; Simpson et al. 2011). Polyphenism is an extreme form of phenotypic plasticity, which is intrinsic to all organisms and biological processes (WestEberhard 2003; Pigliucci et al. 2006; Fusco and Minelli 2010; Moczek 2010). Polyphenisms enable 
insects to partition life history stages, adopt different phenotypes in different life history stages, cope with temporally heterogeneous environments, and in eusocial insects, permits the division of labor (Fusco and Minelli 2010; Simpson et al. 2011).

The environmental cues that trigger phenotypic shifts in insects are diverse, as are the polyphenisms they induce. In some insects, such as the desert locust (Schistocerca gregaria), local shifts in population density induce phenotypic changes, a process known as density-dependent phase polyphenism (Applebaum and Heifetz 1999; Pener and Simpson 2009; Fusco and Minelli 2010). Locusts respond to an increase in population density by shifting from a lone-living, cryptic solitarious phase to a swarming gregarious phase. The extreme solitarious and gregarious phases show striking differences in their coloration, morphology, behavior, metabolism, physiology, neurobiology, immunology, reproduction and ecology, with differences between the two phases being at least as significant as between two closely related species. These phase characteristics can be shifted in either direction, from solitarious to gregarious or vice versa, within the lifetime of an individual (Roessingh and Simpson 1994; Heifetz et al. 1996; Gillett 1988).

Phase change in desert locusts is an adaptation to arid habitats where rains are infrequent and non-periodical but substantial at times. Transitory periods of abundant plant growth after such rains support a rapid population increase of solitarious locusts. However, resources are exhausted rapidly, leaving large numbers of solitarious locusts competing for small patches of vegetation. As the population density increases, physical contact between conspecifics also increases, and it is the persistence of this forced crowding that triggers gregarization (Uvarov 1966, 1977; Roffey and Popov 1968; Simpson et al. 1999; Despland et al. 2000; Culmsee 2002; Sword 2003; Pener and Simpson 2009).

Behavior is the first characteristic to be modified by crowding, with solitarious locusts acquiring key behavioral characteristics of the gregarious phase within $4-8 \mathrm{~h}$ of crowding, including increased activity and locomotion and the propensity to aggregate (Roessingh et al. 1993; Bouaïchi et al. 1995; Simpson et al. 1999; Bouaïchi and Simpson 2003). The initial behavioral shift from avoidance to attraction sets up a positive feedback loop that facilitates all subsequent phase-related phenotypic changes and amplifies phase change from the individual to the population level (Despland et al. 2000; Bouaïchi and Simpson 2003). Morphological and physiological modifications only occur in subsequent stadia or generations
(Pener 1991; Roessingh et al. 1993; Roessingh and Simpson 1994; Applebaum and Heifetz 1999; Simpson et al. 1999; Pener and Simpson 2009; Simpson and Sword 2009), with a maternal epigenetic mechanism contributing to the trans-generational accumulation of phase characteristics (Miller et al. 2008; Tanaka and Maeno 2010).

Desert locusts are polyphagous generalists that feed on a variety of plant species, but their dietary range is phase-dependent. Compared with solitarious locusts, gregarious locusts have a broader diet, consuming a larger number of plant species and engaging in cannibalism (Simpson and Abisgold 1985; Mainguet et al. 2000; Simpson and Raubenheimer 2000; Despland and Simpson 2005a; Bazazi et al. 2008). Gregarization also entails a switch in antipredator strategy from crypsis in solitarious locusts to aposematism in gregarious locusts. Gregarious nymphs are black upon hatching and develop a conspicuous black and bright-yellow pattern in later instars; adult gregarious locusts also show a conspicuous yellow coloration that reflects their aposematic defense strategy (Sword 2002). Gregarious locusts can acquire toxicity only through feeding, however, and must, therefore, forage and consume plant species that contain toxic secondary compounds (Sword et al. 2000; Sword 2002; Despland and Simpson 2005a, 2005b). Consequently, the same insect species can present two distinctly different life history strategies, in which learning and memory abilities may have different relative costs and benefits.

\section{Associative learning in desert locusts}

A variety of behavioral paradigms demonstrate that locusts, and acridids in general, can associate olfactory, gustatory, visual, or positional cues with the nutritional value and the magnitude of either plant material or synthetic diets, and can retain single-meal aversive memories for 2 days (e.g., Simpson and White 1990; Lee and Bernays 1990; Holliday and Holliday 1995; Raubenheimer and Tucker 1997; Behmer et al. 1999, 2005; Pompilio et al. 2006; Dukas and Simpson 2009). More recently, adult desert locusts have also been shown to associate odors with appetitive or aversive food reinforcers in a strictly Pavlovian paradigm without any operant component during training (Simões et al. 2011, 2012, 2013), as do many other insect species (e.g., Bitterman et al. 1983; Tully and Quinn 1985; Matsumoto and Mizunami 2000; Watanabe et al. 2003; Bleeker et al. 2006). In this classical Pavlovian paradigm, locusts are fully restrained during training. The palp opening reflex (POR; Box 1) permits testing 
appetitive memory in the same restrained setting (Simões et al. 2011). Moreover, desert locusts can transfer these classically conditioned olfactory memories to operant contexts: locusts that were restrained during appetitive or aversive associative conditioning make appropriate decisions in a Y-maze arena (Simões et al. 2011, 2013). This confirms the behavioral relevance of Pavlovian associative memories in freely moving locusts and demonstrates that olfactory associative memories are resistant to context changes, as they are in other insects (Tully and Quinn 1985; Sandoz et al. 2000; Matsumoto and Mizunami 2002; Chaffiol et al. 2005).

In locusts, learning contributes to the regulation of feeding, either through neophilia (Bernays and Raubenheimer 1991; Bright et al. 1994; Chambers et al. 1996), habituation of an initially strong rejection of toxin-treated food plants (Szentesi and Bernays 1984) or associative learning (e.g., Simpson and White 1990; Raubenheimer and Blackshaw 1994; Raubenheimer and Tucker 1997; Simões et al. 2011, 2012). Most remarkably, locust can associate odors, color cues, and food locations with specific nutrients within foods (Simpson and White 1990; Raubenheimer and Tucker 1997), and can acquire associative food aversions to nutritionally deficient foods (Champagne and Bernays 1991; Behmer et al. 1999) or toxic chemicals (Bernays and Lee 1988; Lee and Bernays 1990; Simões et al. 2012, 2013) through post-ingestive mechanisms (Box 2). This impressive array of learning mechanisms appears to be related to being polyphagous generalists that must make decisions about which plants to feed on under competitive pressure. Moreover, each food item presents a complex and variable mixture of nutrients and deterrent or toxic compounds, all of which require evaluation and may be informative for subsequent encounters (Bernays 1993; Simpson and Raubenheimer 2000).

\section{Memory dynamics}

Appetitive and aversive memories have different dynamics in locusts (Simões et al. 2011, 2012, 2013). The strength of appetitive memories is positively correlated with the number of conditioning trials; increased conditioning eliciting stronger and prolonged appetitive memories (Simões et al. 2011). In ecological terms, this might indicate that a single feeding bout and the associative pairing it produces becomes relevant and informative in the long term only if followed by further identical, but short-spaced, feeding events.

In aversive conditioning, in contrast, a single paired presentation of odor and nicotine hydrogen tartrate (NHT; 10\%) is sufficient to produce and saturate the locusts' aversive response for at least $24 \mathrm{~h}$ (Bernays and Lee 1988; Lee and Bernays 1990; Simões et al. 2012, 2013). Moreover, in gregarious locusts, the strength of the aversive response depends upon the concentration of toxin but not on the number of trials (Simões et al. 2012). This lack of sensitivity to the number of aversive conditioning trials may be due to the relatively high NHT concentration used as the unconditioned stimulus (US), which causes toxic malaise and activates post-ingestive aversive mechanisms (Box 2).

The long-lasting memories of punishment in locusts contrast with the lesser, non-illness inducing punishments in other insect learning studies (Tully and Quinn 1985; Unoki et al. 2005; Honjo and Furukubo-Tokunaga 2009). In both crickets (Unoki et al. 2005: salt as US) and fruit flies (Tempel et al. 1983; Honjo and Furukubo-Tokunaga 2009: quinine or salt as US), olfactory aversive memories are relatively short-lived compared to appetitive memories, even accounting for the initial levels of memory acquisition. Consequently, in crickets and flies, memories of punishment decay even when the number of trials is large and initial acquisition is high, whereas reward memories show little decay even when the number of trials is small and the level of initial acquisition is low (Mizunami and Matsumoto 2010). It is likely that these species differences in acquisition and decay reflect not only differences in the training protocols, but also the very different feeding ecologies of fruit flies, crickets, and locusts. Work on locusts reviewed in the next sections shows how, in the case of polyphenic insects, ecological differences can be reflected in different learning rules even within one species.

\section{Phase-dependent associative learning}

Desert locusts show phase-dependent aversive, but not appetitive, associative memories. Furthermore, this phase difference in aversive learning is specific to the acquisition but not to the retention or retrieval of long-term memories (Simões et al. 2013): When an unfamiliar odor is paired with NHT-diet, solitarious locusts manifest conditioned aversion to the odor within $10 \mathrm{~min}$ after training. In contrast, the aversion of the conditioned stimulus (CS) odor manifests only gradually after conditioning in gregarious locusts but reaches a comparable magnitude. Remarkably, the process of gregarization through crowding temporarily impairs the acquisition of aversive but not appetitive associative memories (Simões et al. 2013): conditioning of recently 
crowded "transiens" locusts fails to induce any conditioned odor aversion to the toxic alkaloids used in training. This temporary block operates for at least $24 \mathrm{~h}$ after the onset of crowding and is particularly remarkable because, in the case of NHT, the training causes a pronounced toxic malaise that, in long-term gregarious locusts, very effectively engages the postingestive learning pathway (Box 2).

\section{Proximate mechanisms of phase-depen- dent associative learning}

What are the proximate explanations of these observed phase differences in the acquisition of aversive odor-food associations? The explanation cannot lie in any phase-specific differences in odor sensitivity, reception or processing, because all phases show comparable naïve odor discrimination between the odors used in conditioning, and show comparable acquisition of appetitive memories. Moreover, no differences between phases have been reported in the sensitivity or range of olfactory receptor neurons (Ochieng' and Hansson 1999) or in the responses of antennal lobe neurons to plant volatiles (Anton et al. 2002).

The conditioned aversion in solitarious locusts manifests too soon to involve post-ingestive feedback and its acquisition must, therefore, be mediated by detection of the aversive taste of the toxin by gustatory receptors on the mouthparts. This fast tastemediated pathway is strongly down-regulated in long-term gregarious locusts, which rely primarily on post-ingestive feedback for their conditioned aversion (Simões et al. 2012). The apparent disregard of gregarious locusts for the taste of the toxin could be peripheral or central. In the sensory periphery, the phase-dependent acquisition of aversion could be related to phase differences in taste receptor sensitivity to toxins, and specifically to NHT. Precedence for such a peripheral mechanism comes from work that uncovered how the morphology and physiology of the gustatory sensilla in the palps changes according to a locust's nutritional status: the apical pores of the gustatory sensilla, the functional area that contacts with the probed substratum, are open in starved locusts but closed after feeding (Bernays et al. 1972; Blaney and Simmonds 1990). Additionally, as the time since the last feed increases, so the mouthpart taste receptors become increasingly more sensitive to depleted nutrients (Simpson et al. 1991; Simpson and Simpson 1992). Such feeding-dependent changes at the gustatory receptors could lead to a distortion on the perception when food items are probed and may explain how the perceived magnitude of a reward is higher in locusts when training was conducted at lower nutritional states, or state-dependent learned valuation (Pompilio et al. 2006).

Thus, gregarization may elicit fast and long-lasting changes in the receptive properties of the gustatory receptors that could underlie phase-specific taste sensitivity to toxins. The rapid acquisition of aversive memories in solitarious locusts may arise from a higher sensitivity of their taste receptors to toxins, while in gregarious locusts acquisition of aversion would rely more heavily in post-ingestive mechanisms (Simões et al. 2012). The lack of the rapid aversion learning to toxins in the transiens phase (Simões et al. 2013) may be likewise explained by a lack of sensitivity of the gustatory receptors. However, changes in taste receptor sensitivity are an unlikely explanation for the lack of the delayed aversive response in transiens locusts, which indicates that the post-ingestive pathway is strongly down-regulated in these locusts.

Alternatively, phase differences in learning may be related to differences in the central processing of afferent sensory information rather than peripheral processes. Phase differences in some aspects of central processing are evident from differences in the size and proportional composition of their brains that include greatly enlarged primary calyces of the mushroom bodies in the gregarious phase $(\sim 50 \%$ larger in absolute size, $\sim 20 \%$ larger relative to the size of the brain; Ott and Rogers 2010). Therefore, differences in learning and memory in long-term solitarious and long-term gregarious locusts may be a consequence of their neuroanatomical differences, though they are unlikely to account for the rapid changes in aversive memory acquisition following crowding.

It is also possible that the observed differences in aversive learning between phases are related to different dynamics of the neuroaminergic systems that putatively convey the punishment signal to the locusts' brain. In honeybees, pre- and post-ingestive punishment signals are conveyed by dopamine and serotonin, respectively (Wright et al. 2010). The concentrations of serotonin and dopamine are substantially higher in the central nervous system (CNS) of solitarious compared to gregarious locusts, though octopamine is not (Morton and Evans 1983; Rogers et al. 2004). These higher serotonin and dopamine concentrations may lead to lower activation thresholds of the systems conveying the punishment reinforcement signals, causing a faster acquisition of aversion. However, whether the instructive function of these neuroaminergic systems in associative learning, and consequently the strength of associative acquisition, is modulated by relative neuroamine concentrations in the CNS is unknown. 
Furthermore, crowding solitarious locusts elicits complex and rapid changes in the concentrations of the neuroamines implicated in associative learning (Rogers et al. 2004). The rapid increase in serotonin in the thoracic ganglia is the key neuromodulatory signal for the initiation of gregarization in desert locusts (Anstey et al. 2009). On the other hand, there is only a slight increase in the dopamine concentration in the CNS of the transiens locusts when compared with that of solitarious locusts (Rogers et al. 2004). Interestingly, after $4 \mathrm{~h}$ of crowding octopamine decreases to undetectable levels throughout the CNS, whereas after $24 \mathrm{~h}$ of crowding levels in the brain are similar to that in long-term phases, but show a significant increase in the thoracic ganglia and in the optic lobes (Rogers et al. 2004). These changes in total amounts of amines in the nervous tissues cannot, in themselves, provide a mechanistic understanding, but they indicate that crowding has pronounced effects on neuroamine signaling, which may in turn underpin the changes in learning.

As described above, crowding solitarious locusts leads to a temporary impairment of the acquisition of aversive memories (Simões et al. 2013). However, it remains unclear whether the stimuli that have been identified as initiating classical behavioral gregarization in desert locusts are the same as those that affect the aversive learning in the transiens locusts. Behavioral gregarization is classically defined through a set of traits that are measured in an arena assay (Roessingh et al. 1993) and include increased activity, locomotion, and attraction to conspecifics. These traits change in concert, and this concerted change is initiated by two independent sensory pathways: mechanosensory stimulation of the hind legs, and a combination of (as yet uncharacterized) visual and olfactory cues from other locusts (Roessingh et al. 1998; Simpson et al. 2001; Rogers et al. 2003). It is possible that changes in aversive learning happen downstream of the initiation point of the gregarization process, so that they too can be initiated by touch stimuli to the hindlegs. Alternatively, it is conceivable that classical behavioral gregarization and the impairment of aversive learning occur in parallel and require different cues from conspecifics. In honeybees, pheromonal input can specifically block appetitive (Urlacher et al. 2010) or aversive associative learning (Vergoz et al. 2007). Conceivably, locust pheromones such as the bacterially derived fecal volatile guaiacol (Dillon et al. 2000; Pener and Simpson 2009) may likewise be sufficient to induce the observed changes in aversive learning while tactile stimuli that trigger classical gregarization may be ineffective.

\section{Phase-dependent reinforcement valuation}

A phase-dependent reinforcement valuation in desert locusts is supported by the results of conditioning with hyoscyamine (HSC). With this alkaloid as the US during associative conditioning, solitarious locusts acquire a conditioned aversion to the odor, whereas gregarious and transiens locusts do not (Simões et al. 2013). Moreover, solitarious locusts can be appetitively conditioned with HSC if retrained after the onset of crowding, indicating that gregarization is a key factor in the assignment of the reinforcement value for this toxin.

HSC is a toxic alkaloid present in Hyoscyamus muticus, a plant present in the natural range of the desert locusts and one of the gregarious desert locust's preferred food plants (Popov et al. 1991). When added to an artificial diet, HSC induces phase-dependent ingestion behavior in free feeding tests; solitarious locusts avoid and discriminate against HSC, whereas gregarious and transiens locusts readily accept the alkaloid (Despland and Simpson 2005a, 2005b). In the context of associative learning, the reinforcement value of HSC is, therefore, related directly to the feeding behavior by each phase. This indicates that the phase-dependent reinforcement valuation and the phase-dependent ingestion of HSC may share the same underlying mechanism. This mechanism is unknown but it may rely on fast, adaptive changes in the reception and/or perception of the toxins. It is also unknown whether desert locusts show similar phase-dependent feeding on other toxins (Despland 2005).

The phase-dependent intake of HSC reflects the different anti-predator strategies used by desert locusts (Sword et al. 2000; Despland and Simpson 2005a, 2005b). Solitarious locusts are crepuscular or nocturnal and rely on crypsis as their main antipredator strategy: they have green or sandy coloration as nymphs, whereas adults are beige-brown to blend in with their background (Fig. 1). In contrast, gregarious locusts adopt an aposematic strategy, ingesting toxic plants and using bright warning coloration to advertise their unpalatability to predators (Sword et al. 2000; Despland and Simpson 2005a). During gregarization, the shift from crypsis to aposematism happens in two stages and reflects the inevitable lag between the rapid behavioral transition and the change in body color. Behaviorally gregarized transiens locusts broaden their diet by feeding on toxic plants, while the change in coloration does not occur until their next molt (Despland and Simpson 2005a, 2005b). Thus, it is probable that 


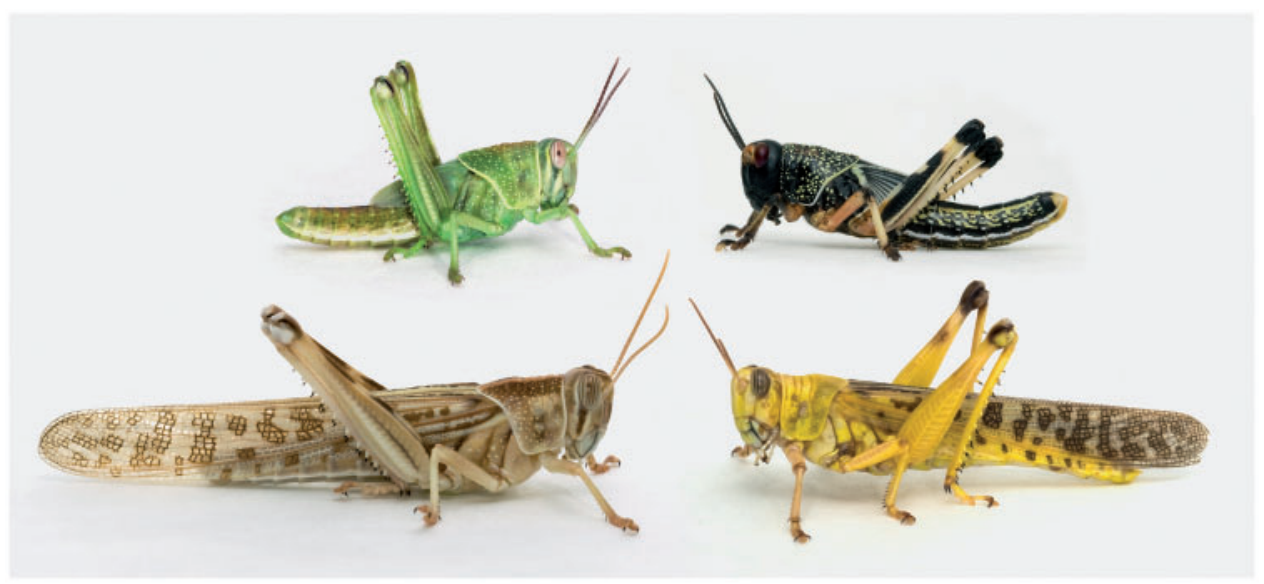

Fig. 1 Solitarious and gregarious locusts differ in their external morphology. Although there are differences in body size and shape, the most obvious difference is that larval (upper, left) and adult (lower, left) solitarious locusts are camouflaged, whereas larval (upper, right) and adult (lower, right) gregarious locusts are aposematic. Modified from Burrows et al. (2011).

the phase-dependent reinforcement valuation observed in desert locusts is an adaptation that serves not to optimize dietary breadth within each phase, but rather to support different feeding behaviors underlying different anti-predator strategies.

Transiens locusts rapidly change their feeding behavior in response to gregarization (Despland and Simpson 2005a, 2005b), with direct consequences on the reinforcement value of toxins. Indeed, gregarization elicits a period in which transiens locusts do not acquire aversive memories when conditioned with toxins. The initiation of this period appears to be related to changes induced by crowding in the reception or perception and post-ingestive evaluation of toxins, but what defines the end of it? During the crowding-induced change from crypsis to aposematism, transiens locusts are indifferent or perhaps even attracted to toxins to gain unpalatability. It is possible that the end of this period of toxin ingestion (and lack of aversive learning) is related to the concentration of toxins in the gut or hemolymph and is, therefore, determined by the ingestion of toxic plants. This may be analogous to the modulation of the feeding behavior by the concentration of nutrients on the locusts' hemolymph (Simpson et al. 1991; Simpson and Simpson 1992). On the other hand, it may be that the period is a specific temporal window, a critical period.

\section{The persistence of memories through- out gregarization}

Phase change, and gregarization in particular, could be considered a stressful condition, stress being defined as any condition that requires physiological or behavioral modification for maintaining the wellbeing of the organism (Selye 1973). Stress can impair or facilitate learning and memory (Shors 2004), and crowding within $1 \mathrm{~h}$ after training impairs long-term memory formation in pond snails (De Caigny and Lukowiak 2008; Lukowiak et al. 2010). Given the magnitude of the phenotypic response to crowding in locusts, it is remarkable that gregarization does not disrupt associative memories acquired immediately before the initiation of the process (Simões et al. 2013); transiens locusts retain both appetitive and aversive memories and retrieve them appropriately after crowding. Thus, unlike in snails, memory consolidation is not affected by crowding, which may reflect an adaptation to the central role of changing population densities in locust biology. A paradoxical consequence, however, of this persistence of memories is that transiens locusts are "stuck" with aversive odor-toxin associations that are no longer ecologically appropriate. Conversion to an appetitive association occurs only when the transiens locust feeds once more, in the presence of the odor, on the HSC-containing food, and is supported by the specific block of aversive learning (Simões et al. 2013). In the field, where crowding is driven by host plant depletion and starved transiens locusts are likely to resample toxic plants, this solution would seem to enable the selective updating of associations between odors and toxic food without compromising other memories.

\section{Conclusions}

Polyphenisms are one of the most extreme forms of phenotypic plasticity and are particularly common in 


\section{Box 1. The locust POR}

The POR of desert locusts (Simões et al. 2011; Fig. 2) is analogous to the most studied behavioral measure of associative memory in insects, the proboscis extension reflex (PER) of the honeybee, which shows rapid, reliable, and long-lasting olfactory conditioning (Bitterman et al. 1983; Hammer and Menzel 1995). Similarly high conditioned PER rates are seen in other insect species with a proboscis, such as moths (Hartlieb 1996; Fan et al. 1997) and fruit flies (Chabaud et al. 2006), although exceptions do exist (e.g., bumblebees: Laloi et al. 1999). The conditioned response rate of the locust POR is, however, lower than the honeybee PER, and similar to that of the maxilla-labium extension response in the ant Camponotus aethiops, the first non-invasive behavioral measure of associative acquisition in a restrained insect without a proboscis (Guerrieri and d'Ettorre 2010). The conditioned response rate of the PER may be higher because in species with a proboscis, its extension is a mechanical prerequisite for ingestion. Consequently, the neural control of the PER might be tightly coupled to the neural circuit that initiates the licking motor pattern (Rehder 1987). In contrast, locust palps are essentially accessory feeding structures for probing and manipulating food (Blaney and Chapman 1970) that are not indispensable for ingestion, and, therefore, their motor control may not be as tightly coupled to chewing and ingestion. Nonetheless, the POR is currently used as a robust behavioral measure of memory acquisition in physiological studies on locust olfaction (Saha et al. 2013, 2015).
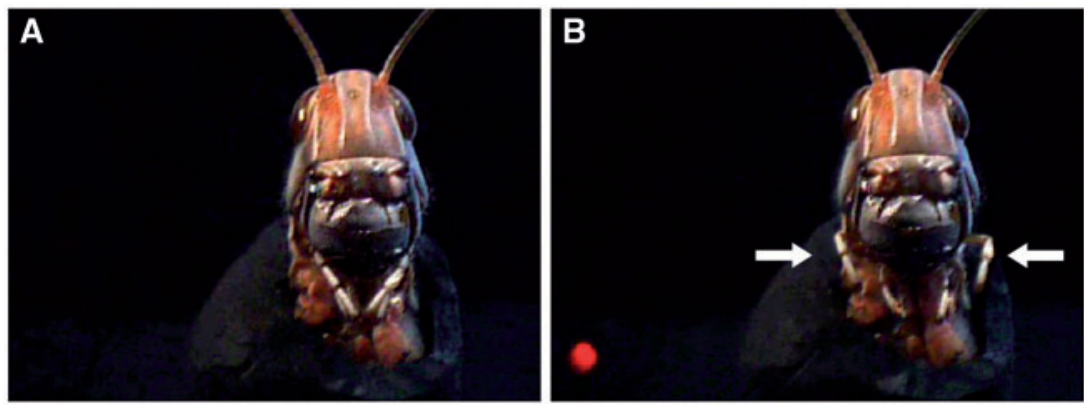

Fig. 2 The POR of the desert locust. (A) The maxillary palps are initially held loosely. (B) Upon presentation of the trained odor the palps are raised and moved apart. Figure modified from Simões et al. (2011).

insects, where a single genome has the capacity to produce distinct phenotypes with major morphological, physiological, and behavioral differences to cope in different environments (Nijhout 2003; WestEberhard 2003; Fusco and Minelli 2010; Moczek 2010; Simpson et al. 2011). Animals can also exploit new environments by learning and storing information about specific environmental characteristics. Thus, learning can be seen as a mechanism of behavioral plasticity animals use to improve their feeding, predator avoidance, or sexual behaviors (Thorpe 1963; Shettleworth 1972; Hinde and StevensonHinde 1973; Papaj and Prokopy 1989; Dukas 2008a; Chittka and Niven 2009).

The desert locusts' remarkable density-dependent polyphenism is reflected in the phase differences in the acquisition of aversive associative memories. The process of phase change, and gregarization in particular, is a key factor in the assignment of the reinforcement value for toxins. Long-term gregarious locusts can learn olfactory aversions through post- ingestive toxic inputs enabling them, in conjunction with peripheral processes, to reduce the risk of toxic poisoning and improve their survival. Associative memories acquired prior to gregarization are not influenced or disrupted by the phase change process. The phase-dependent reinforcement valuation is a consequence of the changes in the feeding behavior that follows desert locusts' phase change. Thus, the neuroecology of learning in desert locusts appears to be related to a switch in the antipredator strategy from crypsis in solitarious locusts to aposematism in gregarious locusts. Overall, these observations demonstrate that polyphenism can produce striking differences and rapid changes in the learning capabilities between distinct phenotypes. Furthermore, the fact that memories can be maintained while the mechanisms for memory acquisition are altered during phase transition show that the polyphenic process can have a specific, rather than a general, influence on the learning mechanisms, even when an animal is undergoing extensive behavioral and 


\section{Box 2. Long-latency aversive learning in gregarious locusts}

Locusts use post-ingestive mechanisms to acquire associative aversions to nutritionally deficient or toxic foods (Bernays and Lee 1988; Lee and Bernays 1990; Champagne and Bernays 1991; Behmer et al. 1999; Simões et al. 2012). Locusts have taste receptors that respond to NHT and other alkaloids (White and Chapman 1990; Chapman et al. 1991), but the post-ingestive aversion learning in gregarious locusts is independent of the gustatory cues from the toxin (Simões et al. 2012). The olfactory aversion of gregarious locusts to NHT is gradual and concentration dependent: they show no aversive response shortly after training, their aversion increasing gradually, reaching a maximum $4 \mathrm{~h}$ later and lasting for at least one day (Simões et al. 2012). These long latencies may be due to the time taken for the toxin to pass through the gut and reach a threshold concentration in the hemolymph. The post-ingestive mechanism enables gregarious locusts to form associations between odors and noxiously evoked internal signals, even when separated by up to $30 \mathrm{~min}$. The neural circuits in the locust olfactory system are unlikely to maintain olfactory representations for up to $30 \mathrm{~min}$. Instead, Simões et al. (2012) suggested that the noxiously evoked post-ingestive feedback may update the value of an initially appetitive labile memory between the odor and feeding. The putative initial positive reinforcement may be due to ingestion, the feeding behavior itself or internal taste receptors or stretch receptors from the gut (Abisgold and Simpson 1987). The requirement for ingestion to be simultaneous with an odor safeguards against the attribution of the toxic malaise to "non-causal" odors.

physiological reorganization. Finally, the learning capabilities of each phenotype appear not to be a side effect of the phenotypic plasticity, but rather integrated with their particular life history strategy employed to cope with different environments.

\section{Acknowledgments}

We thank Jeff Riffell and Ashley Rowe for organizing the symposium, and three referees for comments on a previous version of the manuscript.

\section{Funding}

This work was supported by a $\mathrm{PhD}$ studentship from the Fundação para a Ciência e Tecnologia [SFRH/ BD/33278/2007 to P.M.V.S.]; a Royal Society University Research Fellowship, research project grant [F/09 364/K to S.R.O.] from the Leverhulme Trust and research grants $[\mathrm{BB} / \mathrm{H} 002537 / 1$ and BB/ L02389X/1 to S.R.O.] from the BBSRC; and a Royal Society University Research Fellowship and the School of Life Sciences, University of Sussex, UK [to J.E.N.].

\section{References}

Abisgold J, Simpson S. 1987. The physiology of compensation by locusts for changes in dietary protein. J Exp Biol 129:329-46.

Anstey ML, Rogers SM, Ott SR, Burrows M, Simpson SJ. 2009. Serotonin mediates behavioral gregarization underlying swarm formation in desert locusts. Science 323:627-30.

Anton S, Ignell R, Hansson BS. 2002. Developmental changes in the structure and function of the central olfactory system in gregarious and solitary desert locusts. Microsc Res Techniq 56:281-91.

Applebaum SW, Heifetz Y. 1999. Density-dependent physiological phase in insects. Annu Rev Entomol 44:317-41.

Bazazi S, Buhl J, Hale JJ, Anstey ML, Sword GA, Simpson SJ, Couzin ID. 2008. Collective motion and cannibalism in locust migratory bands. Curr Biol 18:1-5.

Behmer S, Elias D, Bernays EA. 1999. Post-ingestive feedbacks and associative learning regulate the intake of unsuitable sterols in a generalist grasshopper. J Exp Biol 202:739-48.

Behmer ST, Belt CE, Shapiro MS. 2005. Variable rewards and discrimination ability in an insect herbivore: what and how does a hungry locust learn? J Exp Biol 208:3463-73.

Bernays EA. (1993). Aversion learning and feeding. In: Papaj DR, Lewis AC, editors. Insect learning: ecological and evolutionary perspectives. New York (NY): Chapman and Hall. p. $1-17$.

Bernays EA, Blaney WM, Chapman RF. 1972. Changes in chemoreceptor sensilla on the maxillary palps of Locusta migratoria in relation to feeding. J Exp Biol 57:745-53.

Bernays EA, Lee J. 1988. Food aversion learning in the polyphagous grasshopper Schistocerca americana. Physiol Entomol 13:131-7.

Bernays EA, Raubenheimer D. 1991. Dietary mixing in grasshoppers: changes in acceptability of different plant secondary compounds associated with low levels of dietary proteins. J Insect Behav 4:545-56.

Bitterman ME, Menzel R, Fietz A, Schäfer S. 1983. Classical conditioning of proboscis extension in honeybees (Apis mellifera). J Comp Psychol 97:107-19.

Blaney W, Chapman R. 1970. The functions of the maxillary palps of Acrididae (Orthoptera). Entomol Exp Appl 13:363-76.

Blaney WM, Simmonds MSJ. (1990). The chemoreceptors. In: Chapman RF, Joern A, editors. Biology of grasshoppers. New York (NY): J. Wiley \& Sons Inc. p. 1-37. 
Bleeker MAK, Smid HM, Steidle JLM, Kruidhof M, van Loon JJA, Vet LEM. 2006. Differences in memory dynamics between two closely related parasitoid wasp species. Anim Behav 71:1343-50.

Bouaïchi A, Roessingh P, Simpson SJ. 1995. An analysis of the behavioural effects of crowding and re-isolation on solitaryreared adult desert locusts (Schistocerca gregaria) and their offspring. Physiol Entomol 20:199-208.

Bouaïchi A, Simpson SJ. 2003. Density-dependent accumulation of phase characteristics in a natural population of the desert locust Schistocerca gregaria. Physiol Entomol 28:25-31.

Brandes C. 1991. Genetic differences in learning behavior in honeybees (Apis mellifera capensis). Behav Genet 21:271-94.

Bright KL, Bernays EA, Moran VC. 1994. Foraging and dietary mixing in the field by the generalist grasshopper Brachystola magna (Orthoptera: Acrididae). J Insect Behav 7:779-93.

Burrows M, Rogers SM, Ott SR. 2011. Epigenetic remodelling of brain, body and behaviour during phase change in locusts. Neural Systems \& Circuits 1:11.

Burns JG, Foucaud J, Mery F. 2011. Costs of memory: lessons from "mini” brains. Proc R Soc B 278:923-9.

Chabaud MA, Devaud JM, Pham-Delègue MH, Preat T, Kaiser L. 2006. Olfactory conditioning of proboscis activity in Drosophila melanogaster. J Comp Physiol A 192:1335-48.

Chaffiol A, Laloi D, Pham-Delègue MH. 2005. Prior classical olfactory conditioning improves odour-cued flight orientation of honeybees in a wind tunnel. J Exp Biol 208:3731-7.

Chambers P, Sword G, Angel JE, Behmer S, Bernays EA. 1996. Foraging by generalist grasshoppers: two different strategies. Anim Behav 52:155-65.

Champagne DE, Bernays EA. 1991. Phytosterol unsuitability as a factor mediating food aversion learning in the grasshopper Schistocerca americana. Physiol Entomol 16:391400.

Chapman RF, Ascoli-Christensen A, White PR. 1991. Sensory coding for feeding deterrence in the grasshopper Schistocerca americana. J Exp Biol 158:241-58.

Chittka L, Niven J. 2009. Are bigger brains better? Curr Biol 19:995-1008.

Culmsee H. (2002). The habitat functions of vegetation in relation to the behaviour of the desert locust Schistocerca gregaria (Forskål) (Acrididae: Orthoptera) - a study in Mauritania (West Africa). Phytocoenologia 32:645-64.

De Caigny P, Lukowiak K. 2008. Crowding, an environmental stressor, blocks long-term memory formation in Lymnaea. J Exp Biol 211:2678-88.

Despland E. 2005. Diet breadth and anti-predator strategies in desert locusts and other Orthopterans. J Orthopt Res 14:227-33.

Despland E, Collett M, Simpson SJ. 2000. Small-scale processes in desert locust swarm formation: how vegetation patterns influence gregarisation. Oikos 88:652-62.

Despland E, Simpson SJ. 2005a. Food choices of solitarious and gregarious locusts reflect cryptic and aposematic antipredator strategies. Anim Behav 69:471-9.

Despland E, Simpson SJ. 2005b. Surviving the change to warning colouration: density-dependent polyphenism suggests a route for the evolution of aposematism. Chemoecology 15:69-75.

Dillon RJ, Vennard CT, Charnley AK. 2000. Pheromones: exploitation of gut bacteria in the locust. Nature 403, 851.

Dukas R. 1999. Costs of memory: ideas and predictions. J Theor Biol 197:41-50.

Dukas R. 2008a. Evolutionary biology of insect learning. Annu Rev Entomol 53:145-60.

Dukas R. 2008b. Learning decreases heterospecific courtship and mating in fruitflies. Biol Lett 4:645-7.

Dukas R, Bernays EA. 2000. Learning improves growth rate in grasshoppers. Proc Natl Acad Sci 97:2637-40.

Dukas R, Duan JJ. 2000. Potential fitness consequences of associative learning in a parasitoid wasp. Behav Ecol 11:536-43.

Dukas R, Simpson SJ. 2009. Locusts show rapid individual learning but no social learning about food. Anim Behav 78:307-11.

Fan RJ, Anderson P, Hansson BS. 1997. Behavioural analysis of olfactory conditioning in the moth Spodoptera littoralis (Boisd.) (Lepidoptera: Noctuidae). J Exp Biol 200:2969-76.

Ferguson HJ, Cobey S, Smith BH. 2001. Sensitivity to a change in reward is heritable in the honeybee, Apis mellifera. Anim Behav 61:527-34.

Fusco G, Minelli A. 2010. Phenotypic plasticity in development and evolution: facts and concepts. Philos Trans R Soc B 365:547-56.

Gillett SD. 1988. Solitarization in the desert locust, Schistocerca gregaria (Forskal) (Orthoptera: Acrididae). Bull Entomol Res 78:623-31.

Guerrieri FJ, d'Ettorre P. 2010. Associative learning in ants: conditioning of the maxilla-labium extension response in Camponotus aethiops. J Insect Physiol 56:88-92.

Hammer M, Menzel R. 1995. Learning and memory in the honeybee. J Neurosci 15:1617-30.

Hartlieb E. 1996. Olfactory conditioning in the moth Heliothis virescens. Naturwissenschaften 83:87-8.

Heifetz Y, Voet H, Applebaum SW. 1996. Factors affecting behavioural phase transition in the desert locust, Schistocerca gregaria (Forskal) (Orthoptera: Acrididae). J Chem Ecol 22:1717-34.

Hinde RA, Stevenson-Hinde J. (1973). Constraints on learning: limitations and predispositions. London: Academic Press.

Hoedjes KM, Kruidhof HM, Huigens ME, Dicke M, Vet LEM, Smid HM. 2011. Natural variation in learning rate and memory dynamics in parasitoid wasps: opportunities for converging ecology and neuroscience. Proc R Soc B 278:889-97.

Holliday JL, Holliday NJ. 1995. Changes in learning ability and mechanism during development of grasshopper nymphs, Melanoplus bivittatus. Physiol Entomol 20:109-16.

Honjo K, Furukubo-Tokunaga K. 2009. Distinctive neuronal networks and biochemical pathways for appetitive and aversive memory in Drosophila larvae. J Neurosci 29:852-62.

Johnston TD. 1982. Selective costs and benefits in the evolution of learning. Adv Study Behav 12:65-106.

Laloi D, Sandoz JC, Picard-Nizou AL, Marchesi A, Pouvreau A, Taséi JN, Poppy G, Pham-Delègue MH. 1999. Olfactory 
conditioning of the proboscis extension in bumble bees. Entomol Exp Appl 90:123-9.

Lee J, Bernays EA. 1990. Food tastes and toxic effects: associative learning by the polyphagous grasshopper Schistocerca americana (Drury) (Orthoptera: Acrididae). Anim Behav 39:163-73.

Lofdahl KL, Holliday M, Hirsch J. 1992. Selection for conditionability in Drosophila melanogaster. J Comp Psychol 106:172-83.

Lukowiak K, Orr M, De Caigny P, Lukowiak KS, Rosenegger D, Han JI, Dalesman S. 2010. Ecologically relevant stressors modify long-term memory formation in a model system. Behav Brain Res 214:18-24.

Mainguet A, Louveaux A, El-Sayed G, Rollin P. 2000. Ability of a generalist insect, Schistocerca gregaria, to overcome thioglucoside defence in desert plants: tolerance or adaptation? Entomol Exp App 94:309-17.

Matsumoto Y, Mizunami M. 2000. Olfactory learning in the cricket Gryllus bimaculatus. J Exp Biol 203:2581-8.

Matsumoto Y, Mizunami M. 2002. Lifetime olfactory memory in the cricket Gryllus bimaculatus. J Comp Physiol A 188:295-9.

Mery F, Kawecki TJ. 2003. A fitness cost of learning ability in Drosophila melanogaster. Proc R Soc B 270:2465-9.

Mery F, Kawecki TJ. 2004. An operating cost of learning in Drosophila melanogaster. Anim Behav 68:589-98.

Mery F, Kawecki TJ. 2005. A cost of long-term memory in Drosophila. Science 308:1148.

Miller GA, Islam MS, Claridge DW, Dodgson T, Simpson SJ. 2008. Swarm formation in the desert locust (Schistocerca gregaria): isolation and NMR analysis of the primary maternal gregarizing agent. J Exp Biol 211:370-6.

Mizunami M, Matsumoto Y. 2010. Roles of aminergic neurons in formation and recall of associative memory in crickets. Front Behav Neurosci 4:1-11.

Moczek AP. 2010. Phenotypic plasticity and diversity in insects. Philos Trans R Soc B 365:593-603.

Morton DB, Evans PD. 1983. Octopamine distribution in solitarious and gregarious forms of the locust, Schistocerca americana gregaria. Insect Biochem 13:177-83.

Ngumbi E, Jordan M, Fadamiro H. 2012. Comparison of associative learning of host-related plant volatiles in two parasitoids with different degrees of host specificity, Cotesia marginiventris and Microplitis croceipes. Chemoecology 22:207-15.

Nijhout HF. 2003. Development and evolution of adaptive polyphenisms. Evol Dev 5:9-18.

Ochieng' SA, Hansson BS. 1999. Responses of olfactory receptor neurones to behaviourally important odours in gregarious and solitarious desert locust, Schistocerca gregaria. Physiol Entomol 24:28-36.

Ott SR, Rogers SM. 2010. Gregarious desert locusts have substantially larger brains with altered proportions compared with the solitarious phase. Proc R Soc B 277:3087-96.

Papaj DR, Prokopy RJ. 1989. Ecological and evolutionary aspects of learning in phytophagous insects. Annu Rev Entomol 34:315-50.

Pener MP. 1991. Locust phase polymorphism and its endocrine relations. Adv Insect Physiol 23:1-79.
Pener MP, Simpson SJ. 2009. Locust phase polyphenism: an update. Adv Insect Physiol 36:1-286.

Pigliucci M, Murren CJ, Schlichting CD. 2006. Phenotypic plasticity and evolution by genetic assimilation. J Exp Biol 209:2362-7.

Pompilio L, Kacelnik A, Behmer ST. 2006. State-dependent learned valuation drives choice in an invertebrate. Science 311:1613-5.

Popov G, Duranton J, Gigault J. (1991). Etude Ecologique des Biotopes du Criquet Pèlerin Schistocerca gregaria (Forskål, 1775) en Afrique Nord-Occidentale. Mise en évidence et description des unités territoriales écologiquement homogènes. FAO: Rome.

Raine NE, Chittka L. 2008. The correlation of learning speed and natural foraging success in bumble-bees. Proc R Soc B 275:803-8.

Raine NE, Ings TC, Ramos-Rodríguez O, Chittka L. 2006. Intercolony variation in learning performance of a wild British bumblebee population (Hymenoptera: Apidae: Bombus terrestris audax). Entomol Gen 28:241-56.

Raubenheimer D, Blackshaw J. 1994. Locusts learn to associate visual stimuli with drinking. J Insect Behav 7:569-75.

Raubenheimer D, Tucker D. 1997. Associative learning by locusts: pairing of visual cues with consumption of protein and carbohydrate. Anim Behav 54:1449-59.

Rehder V. 1987. Quantification of the honeybee's proboscis reflex by electromyographic recordings. J Insect Physiol 33:501-7.

Roessingh P, Bouaïchi A, Simpson SJ. 1998. Effects of sensory stimuli on the behavioural phase state of the desert locust, Schistocerca gregaria. J Insect Physiol 44:883-93.

Roessingh P, Simpson SJ. 1994. The time course of behavioral phase change in nymphs of the desert locust, Schistocerca gregaria. Physiol Entomol 19:191-7.

Roessingh P, Simpson SJ, James S. 1993. Analysis of phaserelated changes in behavior of desert locust nymphs. Proc $\mathrm{R}$ Soc B 252:43-9.

Roffey J, Popov G. 1968. Environmental and behavioral processes in a desert locust outbreak. Nature 219:446-50.

Rogers SM, Matheson T, Despland E, Dodgson T, Burrows M, Simpson SJ. 2003. Mechanosensory-induced behavioural gregarization in the desert locust Schistocerca gregaria. J Exp Biol 206:3991-4002.

Rogers SM, Matheson T, Sasaki K, Kendrick K, Simpson SJ, Burrows M. 2004. Substantial changes in central nervous system neurotransmitters and neuromodulators accompany phase change in the locust. J Exp Biol 207:3603-17.

Saha D, Leong K, Li C, Peterson S, Siegel G, Raman B. 2013. A spatiotemporal coding mechanism for background-invariant odor recognition. Nat Neurosci 16:1830-9.

Saha D, Li C, Peterson S, Padovano W, Katta N, Raman B. 2015. Behavioural correlates of combinatorial versus temporal features of odour codes. Nat Commun 6:6953.

Sandoz JC, Laloi D, Odoux JF, Pham-Delègue MH. 2000. Olfactory information transfer in the honey bees: compared efficiency of classical conditioning and early exposure. Anim Behav 59:1025-34.

Selye H. 1973. The evolution of the stress concept. Am Sci 61:692-9. 
Shettleworth SJ. 1972. Constraints on learning. Adv Study Behav 4:1-68.

Shettleworth SJ. 1993. Varieties of learning and memory in animals. J Exp Psychol Anim Behav Process 19:5-14.

Shors TJ. 2004. Learning during stressful times. Learn Mem 11:137-44.

Simões PM, Niven JE, Ott SR. 2013. Phenotypic transformation affects associative learning in the desert locust. Curr Biol 23:2407-12.

Simões PMV, Ott SR, Niven JE. 2011. Associative olfactory learning in the desert locust, Schistocerca gregaria. J Exp Biol 214:2495-503.

Simões PMV, Ott SR, Niven JE. 2012. A long-latency aversive learning mechanism enables locusts to avoid odours associated with the consequences of ingesting toxic food. J Exp Biol 215:1711-9.

Simpson SJ, Abisgold JD. 1985. Compensation by locusts for changes in dietary nutrients: behavioural mechanisms. Physiol Entomol 10:443-52.

Simpson SJ, Despland E, Hägele BF, Dodgson T. 2001. Gregarious behaviour in desert locusts is evoked by touching their back legs. Proc Natl Acad Sci 98:3895-7.

Simpson SJ, James S, Simmonds MSJ, Blaney WM. 1991. Variation in chemosensitivity and the control of dietary selection behaviour in the locust. Appetite 17:141-54.

Simpson SJ, McCaffery AR, Hägele BF. 1999. A behavioural analysis of phase change in the desert locust. Biol Rev 74:461-80.

Simpson SJ, Raubenheimer D. 2000. The hungry locust. Adv Study Behav 29:1-44.

Simpson SJ, Simpson CL. 1992. Mechanisms controlling modulation by amino acids of gustatory responsiveness in the locust. J Exp Biol 168:269-87.

Simpson SJ, Sword GA. (2009). Phase polyphenism in locusts: mechanisms, population, consequences, adaptive significance and evolution. In: Whitman DW, Ananthakrishnan TN, editors. Phenotypic plasticity of insects: mechanisms and consequences. Enfield: Science Publishers. p. 147-89.

Simpson SJ, Sword GA, Lo N. 2011. Polyphenism in insects. Curr Biol 21:738-49.

Simpson S, White P. 1990. Associative learning and locust feeding: evidence for a "learned hunger" for protein. Anim Behav 40:506-13.

Sword GA. 2002. A role for phenotypic plasticity in the evolution of aposematism. Proc R Soc B 269:1639-44.

Sword GA. 2003. To be or not to be a locust? A comparative analysis of behavioral phase change in nymphs of
Schistocerca americana and S. gregaria. J Insect Physiol 49:709-17.

Sword GA, Simpson SJ, El Hadi OTM, Wilps H. 2000. Density dependent aposematism in the desert locust. Proc R Soc B 267:63-8.

Szentesi A, Bernays EA. 1984. A study of behavioural habituation to a feeding deterrent in nymphs of Schistocerca gregaria. Physiol Entomol 9:329-40.

Tanaka S, Maeno K. 2010. A review of maternal and embryonic control of phase-dependent progeny characteristics in the desert locust. J Insect Physiol 56:911-8.

Tempel BL, Bonini N, Dawson DR, Quinn WG. 1983. Reward learning in normal and mutant Drosophila. Proc R Soc B 80:1482-6.

Thorpe WH. (1963). Learning and instinct in animals. 2nd ed.. London: Methuen and Co. Ltd.

Tully T, Quinn WG. 1985. Classical conditioning and retention in normal and mutant Drosophila melanogaster. J Comp Physiol A 157:263-77.

Unoki S, Matsumoto Y, Mizunami M. 2005. Participation of octopaminergic reward system and dopaminergic punishment system in insect olfactory learning revealed by pharmacological study. Eur J Neurosci 22:1409-16.

Urlacher E, Francés B, Giurfa M, Devaud JM. 2010. An alarm pheromone modulates appetitive olfactory learning in the honeybee (Apis mellifera). Front Behav Neurosci 4:1-10.

Uvarov B. (1966). Grasshoppers and locusts. Vol. 1. Cambridge: Cambridge University Press.

Uvarov B. (1977). Grasshoppers and locusts. Vol. 2. London: Centre for Overseas Pest Research.

Vergoz V, Schreurs HA, Mercer AR. 2007. Queen pheromone blocks aversive learning in young worker bees. Science 317:384-6.

Watanabe H, Kobayashi Y, Sakura M, Matsumoto Y, Mizunami M. 2003. Classical olfactory conditioning in the cockroach Periplaneta americana. Zool Sci 20:1447-54.

West-Eberhard MJ. (2003). Developmental plasticity and evolution. New York (NY): Oxford University Press.

White PR, Chapman RF. 1990. Tarsal chemoreception in the polyphagous grasshopper Schistocerca americana: behavioural assays, sensilla distribution and electrophysiology. Physiol Entomol 15:105-21.

Wright GA, Mustard JA, Simcock NK, Ross-Taylor AAR, McNicholas LD, Popescu A, Marion-Poll F. 2010. Parallel reinforcement pathways for conditioned food aversions in the honeybee. Curr Biol 20:2234-40. 